\title{
DISTRIBUSI TEMPERATUR RISER PADA POSISI VERTIKAL SELAMA PROSES PEMANASAN MENGGUNAKAN HEATER TIPE-PLAT DI UNTAI UJI RCCS-HTGR
}

\author{
AINUR ROSIDI *, G.B. HERU K., GIARNO, DEDY HARYANTO, HENDRO TJAHJONO, \\ MULYA JUARSA \\ Pusat Teknologi dan Keselamatan Reaktor Nuklir, BATAN \\ Kawasan Puspiptek Serpong, Gedung 80, 15310, \\ Tangerang Selatan, Bantent, Telp. 021-7560912 \\ *email :ainur@batan.go.id
}

\begin{abstract}
Abstrak. Untai uji Reactor Cavity Cooling System (RCCS) adalah fasilitas uji eksperimen yang digunakan untuk mempelajari salah satu sistem keselamatan pada reaktor High Temperature Gas-cooled Reactor (HTGR). Sistem bekerja berdasarkan sirkulasi alamiah dan tidak membutuhkan energi listrik. Untai uji ini memiliki dua komponen utama, yaitu sumber panas terbuat dari heater tipe-plat yang mensimulasikan dinding Reactor Pressure Vessel (RPV) dan dinding riser yang berfungsi untuk penyerapan panas. Tujuan penelitian dilakukan untuk memperoleh karakteristik selama pengujian pemanasan dari dinding riser pada posisi vertikal dalam menyerap panas. Metode pengujian dilakukan dengan memanaskan heater tipe-plat dengan menaikkan daya heater secara bertahap sampai temperatur pada sumber panas tercapai maksimum yaitu $200^{\circ} \mathrm{C}$. Pengukuran temperatur menggunakan termokopel yang dipasang di bagian bawah, tengah dan atas dari dinding riser. Hasil pengujian menunjukan bahwa posisi dinding riser pada bagian atas menghasilkan temperatur yang lebih tinggi sekitar $49.4^{\circ} \mathrm{C}$ dibandingkan posisi bagian bawah dan bagian tengah berkisar antara $33^{\circ} \mathrm{C}-35^{\circ} \mathrm{C}$. Temperatur di dinding riser bagian atas juga membentuk pola zig-zag, yang menunjukkan bahwa aliran sirkulasi alamiah dari fluida kerja udara mulai bekerja secara konveksi alami untuk mendinginkan dinding riser pada untai uji RCCS.
\end{abstract}

Kata kunci: heater tipe-plat, HTGR, sistem pendingin pasif, RCCS, Riser

\begin{abstract}
The Reactor Cavity Cooling System (RCCS) test strand is an experimental test facility used to study one of the safety systems in the High Temperature Gas-cooled Reactor (HTGR). The system works based on natural circulation and does not need electrical energy. This test strand has two main components, namely a heat source made of a plate-type heater that simulates the Reactor Pressure Vessel (RPV) wall and the riser wall which functions for heat absorption. The aim of the research was to obtain the characteristics during the heating test of the riser wall in a vertical position to absorb heat. The test method was carried out by heating the plate-type heater by increasing the heater power gradually until the maximum temperature at the heat source was $200^{\circ} \mathrm{C}$. Temperature measurement using a thermocouple which is installed at the bottom, middle and top of the riser wall. The test results showed that the position of the riser wall at the top resulted in a higher temperature of about $49.4^{\circ} \mathrm{C}$ compared to the lower and middle positions ranging from $33^{\circ} \mathrm{C}-35^{\circ} \mathrm{C}$. The temperature in the upper riser wall also forms a zigzag pattern, which indicates that the natural circulating flow of the working air fluid begins to act naturally by convection to cool the riser wall of the RCCS test strand.
\end{abstract}

Keywords: plate-type heater, HTGR, passive cooling system, RCCS, Riser 


\section{Pendahuluan}

High Temperature Gas-cooled Reactor (HTGR) merupakan reaktor bertemperatur tinggi yang menggunakan pendingin gas dan dirancang dengan Low Enriched Uranium (LEU) [1]. Reaktor ini merupakan reaktor skala Small Medium Reactor (SMR) atau reaktor skala kecil menengah, yang mempunyai fitur keselamatan melekat dan sistem keselamatan pasif dengan mekanisme perpindahan panas alami dari konduksi, konveksi alami, dan radiasi termal [2]. Sehingga mempunyai tingkat keselamatan dan keandalan yang lebih baik, ketika kecelakaan kehilangan pendingin pada HTGR dipostulasikan terjadi, Panas dari peluruhan inti akan dipindahkan secara konduksi melalui reflektor grafit di teras dan radiasi termal dan konveksi alami dari bejana reaktor [3]. Reactor Cavity Cooling System (RCCS) akan membuang panas dari bejana reaktor dengan sirkulasi alami udara luar, RCCS ini selalu beroperasi pada kondisi normal dan kecelakaan dengan sistem pendingin pasif penuh, oleh karena sistem ini tidak memerlukan intervensi dari operator atau tindakan dari sinyal aktuator listrik [4, 5].

Kajian tentang penggunaan RCCS sebagai pendingin pada reaktor jenis HTGR pada waktu terjadi kecelakaan telah dilakukan oleh beberapa peneliti diantaranya adalah Yeong Bae dkk, melakukan eksperimen membuang panas sisa yang berjumlah $0,3-0,6 \%$ dari daya penuh reaktor jenis HTGR melalui radiasi dan konveksi alami, hasil eksperimen menunjukkan RCCS mampu membuang panas sisa dengan baik [6]. Angelo Frisani dkk, telah melakukan desain dan validasi RCCS pada reaktor jenis Very High Temperature Gas-Cooled Reactors ((VHTR), desain ini diperlukan untuk menunjukkan bahwa sistem pendingin RCCS dapat bertahan dan mampu mendinginkan bejana reaktor pada saat terjadi kecelakaan. Hasil simulasi menunjukkan bahwa validasi menggunakan CFD dapat menyerupai perilaku dan fenomena fisik sistem RCCS [7].

Penelitian tentang pengaruh kegagalan desain fungsi RCCS di mana konveksi alami dari udara luar tidak terbentuk telah dilakukan oleh Hong Sik Lim dkk, dengan dipostulasikan cerobong udara runtuh oleh peristiwa eksternal sehingga konveksi udara benar-benar hilang, desain pada RCCS menggunakan 2 fluida kerja pendingin yaitu udara dan air untuk mengurangi panas berlebih pada dinding bejana reaktor. Hasil simulasi menggunakan GAMMA+ code menunjukkan bahwa sistem water jacket dapat berfungsi sebagai sistem cadangan untuk mengurangi panas berlebih dari kecelakaan parah seperti runtuhnya cerobong udara [8]. Kuniyoshi dkk, melalukan desain RCCS dengan model baru sebagai pendingin pada HTGR, menggunakan udara sebagai fluida kerja dan udara ambien sebagai heat sink utama. Hasil simulasi menggukan CFD menunjukkan bahwa distribusi temperatur RCCS berada dalam batas aman temperatur struktur, seperti temperatur operasi maksimum RPV sebesar $440^{\circ} \mathrm{C}$, dan panas yang dilepaskan dari Reactor Pressure Vessel (RPV) dapat dihilangkan dengan aman, bahkan selama kecelakaan kehilangan pendingin. Sehingga RCCS menggunakan desain baru ini secara efisien menghilangkan panas yang dilepaskan dari RPV dengan radiasi dan konveksi alami $[9,10]$.

Dari beberapa literatur mengenai penggunaan RCCS sebagai pendingin pada reaktor jenis HTGR masih belum banyak yang melakukan penelitian dengan eksperimental. Tujuan pada penelitian ini adalah memperoleh distribusi temperatur dinding riser pada posisi vertikal selama proses pemanasan menggunakan heater tipe-plat di untai uji RCCS-HTGR. Metode yang dilakukan dalam penelitian ini adalah eksperimental. Heater tipe-plat diasumsikan sebagai RPV, pemasanan 
dilakukan secara transien sampai temperature $200^{\circ} \mathrm{C}$. Fluida kerja pendingin yang digunakan adalah udara. Penelitian ini dapat digunakan sebagai investigasi awal untuk pengembangan pendinginan pasif menggunakan udara bebas dengan aliran Tipe-U di untai uji RCCS.

\section{Metode Penelitian}

Untai uji RCCS-HTGR adalah fasilitas uji eksperimen yang digunakan untuk mempelajari salah satu sistem keselamatan pada reaktor HTGR, dengan cara mendinginkan reaktor dari panas sisa hasil fisi yang mempengaruhi temperatur dinding konkrit gedung Reactor Pressure Vessel (RPV). Sistem bekerja berdasarkan sirkulasi alamiah, yang tidak membutuhkan energi listrik. Skema Untai uji RCCS-HTGR ditunjukkan pada Gambar 1.

(a)

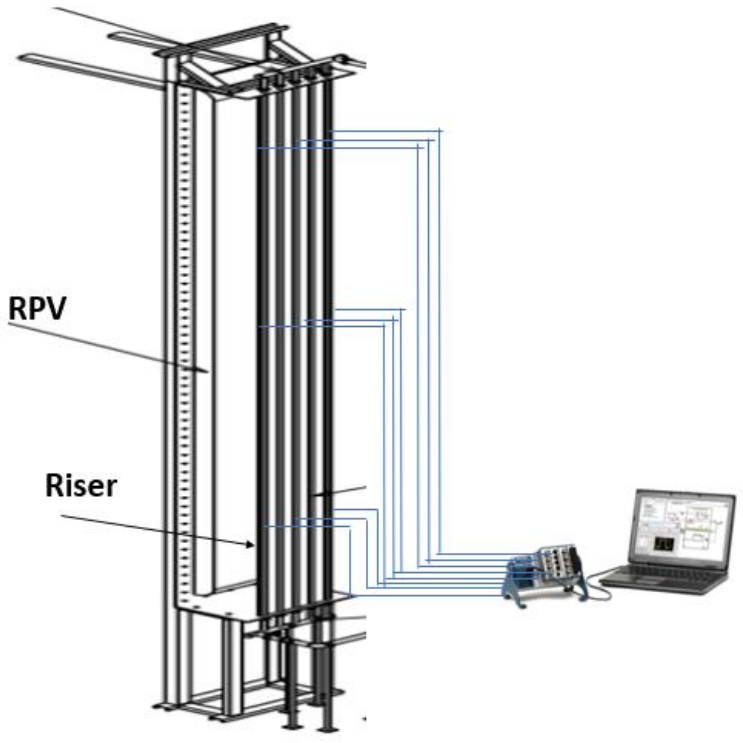

(b)

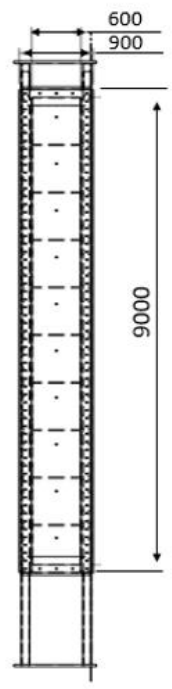

Gambar 1. (a) Skema Untai uji RCCS-HTGR (b) Dimensi RPV pada Untai uji RCCS-HTGR

Komponen utama untai uji RCCS-HTGR terdiri dari dinding heater tipe-plat sebagai sumber panas yang mensimulasikan dinding RPV dan dinding riser yang berfungsi untuk penyerapan panas. Sumber panas pada untai uji ini menggunakan pemanas dengan tipe-plat. Jumlah heater tipe-plat yang dipasang sebanyak 10 buah, 1 heater tipe-plat mempunyai daya sebesar $15 \mathrm{~kW}$ sehingga total daya pada heater tipe-plat $150 \mathrm{~kW}$. Sedangkan dinding riser terbuat dari susunan 5 pipa dan plat dengan material stainless stell 304. Heater tipe-plat dan dinding riser ini dipasang secara vertical dengan ketinggian yang sama yaitu 9 meter dan lebar $60 \mathrm{~cm}$.

Pengukuran temperatur pada dinding riser untai uji RCCS menggunakan termokopel tipe K, termokopel yang dipasang pada eksperimen ini ada 9 titik. Tiga buah termokopel pada dinding riser bagian bawah, 3 buah termokopel pada dinding riser bagian tengah dan 3 termokopel pada dinding riser bagian atas. Penempatan posisi termokopel sepanjang dinding riser untai uji RCCS-HTGR dapat dilihat pada Gambar 2. 


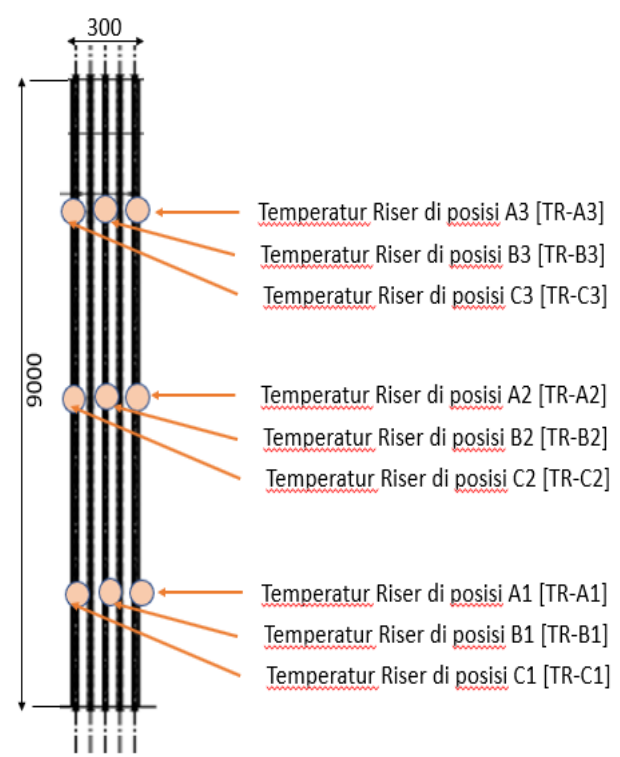

Gambar 2. Penempatan termokopel pada dinding riser untai uji RCCS

Eksperimen dilakukan terlebih dahulu dengan memanaskan heater tipe-plat dengan menaikkan daya heater secara bertahap. Besarnya arus dan tegangan yang masuk ke heater diukur dengan menggunakan tang ampere. Kemudian ketika temperatur pada heater tipe-plat tercapai maksimum yaitu $200^{\circ} \mathrm{C}$ pemanasan tetap di pertahankan secara steady state, kemudian daya dimatikan ketika fluida kerja udara berhasil menurunkan temperatur pada dinding riser untai uji RCCS. Pengambilan data dan perekaman selama eksperimen dari awal sampai akhir dilakukan dengan menggunakan sistem akuisisi data modul National Instrument 9476 dengan virtual instrument software LabVIEW.

\section{Hasil dan Pembahasan}

Hasil eksperimen setelah dilakukan pemberian beban panas untuk 10 heater tipeplat sebesar $150 \mathrm{~kW}$ dan dinding RPV mencapai temperatur $200^{\circ} \mathrm{C}$, didapatkan distribusi temperatur pada dinding riser seperti terlihat pada Gambar 3.

Pada awal pemanasan dinding RPV, penyerapan kalor yang di terima oleh dinding riser dengan mekanisme perpindahan panas alami secara konduksi, konveksi alami, dan radiasi termal mengalami kenaikan temperatur secara perlahan. Setelah detik ke-4000 temperatur pada dinding RPV mengalami kenaikan mencapai $200^{\circ} \mathrm{C}$, yang diikuti dengan kenaikan temperatur secara drastis pada dinding riser bagian atas yaitu TR-A3, TR-B3 dan TR-C3, Temperatur tertinggi rata-rata pada bagian atas sebesar $49^{\circ} \mathrm{C}$ tercapai pada detik ke- 1250 .

Sedangkan pada pada dinding riser bagian bawah dan bagian tengah dari awal pemanasan sampai temperatur di dinding RPV tercapai steady state yaitu sebesar $200^{\circ} \mathrm{C}$, distribusi kenaikan temperaturnya sangat kecil yaitu masing-masing temperatur tertinggi rata-ratanya tercapai $31^{\circ} \mathrm{C}$ dan $34^{\circ} \mathrm{C}$. Pada detik ke-5600 sampai akhir pemanasan di dinding riser bagian atas terbentuk pola zig-zag, hal ini 
menunjukkan bahwa aliran sirkulasi alamiah dari fluida kerja udara mulai bekerja secara konveksi alami untuk mendinginkan riser untai uji RCCS.

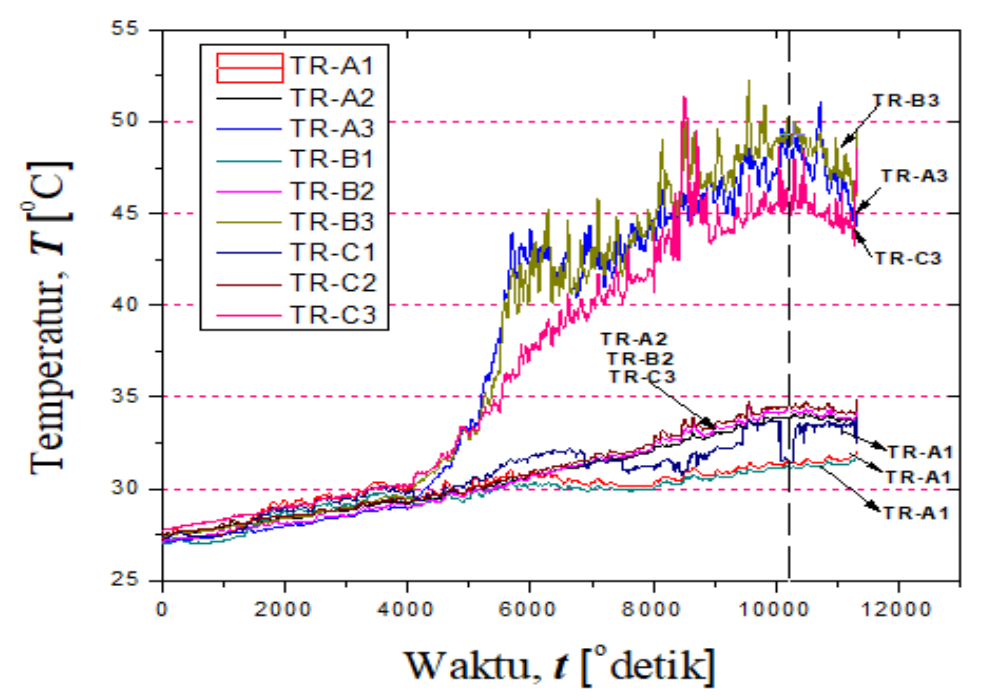

Gambar 3. Kurva temperatur transien pemanasan pada pada dinding riser untai uji RCCS

Untuk mengetahui kinerja dinding riser dalam membuang panas yang dihasilkan dinding RPV, maka perlu diketahui terlebih dahulu distribusi temperatur sepanjang dinding riser pada posisi vertikal. Distribusi temperatur vertikal sepanjang dinding riser untai uji RCCS dapat dilihat pada kurva Gambar 4.

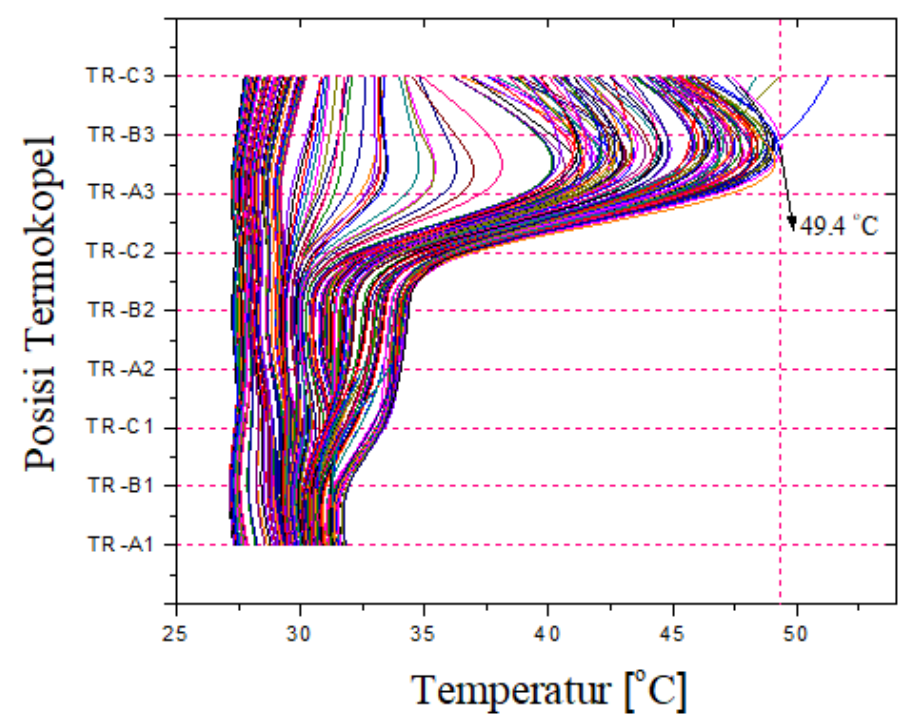

Gambar 4. Kurva isotime distribusi temperatur vertikal pada dinding riser untai uji RCCS

Pada Gambar 4 dapat dilihat bahwa semakin tinggi posisi termokopel menyebabkan semakin tinggi temperatur yang di terima pada dinding riser untai uji RCCS. Pola ini dapat terjadi oleh karna panas yang di serap oleh dinding riser pada bagian tengah dan bagian bawah akan mengalir dan mengumpul ke bagian atas. Hal ini disebabkan oleh karena perbedaan densitas dari fluida kerja udara akibat 
pemanasan, sehingga udara panas mengalir dari posisi bagian bawah dan bagian tengah menuju ke posisi bagian atas.

Distribusi temperatur pada arah horizontal di dinding riser posisi atas menunjukkan bahwa termokopel pada titik B3 yang merupakan posisi tengah mengalami kenaikan lebih tinggi dibandingkan dengan titik A3 dan C3 yang berada di posisi ujung. Hal ini disebabkan karena panas pada titik A3 dan C3 lebih banyak terbuang diudara dan sebagian panasnya mengalir menuju titik B3 secara konduksi.

\section{Kesimpulan}

Berdasarkan hasil eksperimen mengenai distribusi temperatur dinding riser pada posisi vertikal selama proses pemanasan menggunakan heater tipe-plat di untai uji RCCS dapat disimpulkan bahwa posisi dinding riser pada bagian atas menghasilkan temperatur yang lebih tinggi dibandingkan posisi bagian bawah dan bagian tengah. Pada dinding riser bagian atas juga terbentuk pola zig-zag, yang menunjukkan bahwa aliran sirkulasi alamiah dari fluida kerja udara mulai bekerja secara konveksi alami untuk mendinginkan dinding riser pada untai uji RCCS.

\section{Ucapan Terima Kasih}

Penelitian ini didanai oleh DIPA-PTKRN tahun anggaran 2020 dan program Insinas, ucapan terimakasih kepada rekan-rekan BPFKR dan mahasiswa UIKA yang sedang tugas akhir di laboratorium Termohidrolika, atas terselenggaranya kegiatan penelitian ini

\section{Daftar Pustaka}

1. P.H. Liem, et al., Alternative Fueling Scheme for the Indonesian Experimental Power Reactor (10 MWth Pebble-Bed HTGR). Energy Procedia, 2017. 131: p. 69-76.

2. M. Nakano, et al., Core design and safety analyses of $600 \mathrm{MWt}, 950^{\circ} \mathrm{C}$ high temperature gas-cooled reactor. Nuclear Engineering and Design, 2014. 271: p. $560-563$.

3. Q. Sun, et al., Graphite dust emission evaluation in an HTGR depressurization accident. Annals of Nuclear Energy, 2020. 147: p. 107664.

4. S. B. Seo, et al., Risk mitigation strategy by Passive IN-core Cooling system for advanced nuclear reactors. Annals of Nuclear Energy, 2018. 111: p. 554567.

5. K. Takamatsu, et al., Improvement of heat-removal capability using heat conduction on a novel reactor cavity cooling system (RCCS) design with passive safety features through radiation and natural convection. Annals of Nuclear Energy, 2018. 122: p. 201-206.

6. Y. Bae, S.-D. Hong, and Y.-W. Kim, Scaling analysis of PMR200 reactor cavity cooling system. Nuclear Engineering and Design, 2014. 271: p. 523-529.

7. A. Frisani and Y.A. Hassan, Computation fluid dynamics analysis of the Reactor Cavity Cooling System for Very High Temperature Gas-Cooled Reactors. Annals of Nuclear Energy, 2014. 72: p. 257-267. 
8. H.S. Lim, et al., Water-jacket reactor cavity cooling system concept to mitigate severe accident consequence of high temperature gas-cooled reactor. Nuclear Engineering and Design, 2018. 340: p. 156-165.

9. $\mathrm{K}$. Takamatsu and $\mathrm{R}$. $\mathrm{Hu}, \mathrm{New}$ reactor cavity cooling system having passive safety features using novel shape for HTGRs and VHTRs. Annals of Nuclear Energy, 2015. 77: p. 165-171.

10. K. T. Takamatsu, T. Matsumoto, and K. Morita, New reactor cavity cooling system (RCCS) with passive safety features: A comparative methodology between a real RCCS and a scaled-down heat-removal test facility. Annals of Nuclear Energy, 2016. 96: p. 137-147. 